\title{
Tribocorrosion Behavior of Several Corrosion-resistant Alloys Sliding Against CF-PEEK: Application for Hydraulic Valve in Seawater
}

\author{
Fanglong $\mathrm{Yin}^{1}$, Xin Zhou ${ }^{1}$, Songlin $\mathrm{Nie}^{1,{ }^{*}}, \mathrm{Hui} \mathrm{Ji}^{1}$ and Zhen $\mathrm{Hu}^{2}$ \\ ${ }^{1}$ Beijing Key Laboratory of Advanced Manufacturing Technology, Beijing University of Technology, \\ Beijing 100124, China \\ ${ }^{2}$ Department of Industrial and Manufacturing Systems Engineering, University of Michigan-Dearborn, \\ Dearborn, MI 48128, USA \\ *E-mail: niesonglin@ bjut.edu.cn
}

doi: $10.20964 / 2019.05 .66$

Received: 22 October 2018 / Accepted: 22 December 2018 / Published: 10 April 2019

To select appropriate combinations of antifriction and wear-resistant materials for key tribopairs in seawater hydraulic valves, the tribocorrosion behavior of six kinds of corrosion-resistant alloys sliding against a carbon fiber/polytetrafluoroethylene/graphite (CF/PTFE/graphite)-filled polyetheretherketone (CF-PEEK) composite under artificial seawater lubrication was comparatively investigated by using a pin-on-disk friction tester and electrochemical workstation. The results show that AISI 316, AISI 630 and chromium-plated Ti6Al4V exhibit better tribological behavior than Ti6Al4V and nitrided Ti6Al4V under dry friction, distilled water and artificial seawater conditions. Besides, Ti6Al4V exhibits better corrosion resistance than other corrosion-resistant alloys in both static corrosion and tribocorrosion conditions, and the chromium plating process significantly accelerates the Ti6Al4V corrosion rate in seawater. Moreover, the corrosion-induced wear is higher than the wear-induced corrosion. In addition, the contribution of corrosion-induced wear to synergetic weight loss is more than $85 \%$ for all the alloys under tribocorrosion in seawater. Consequently, material combinations of AISI 630/CF-PEEK and AISI 316/CF-PEEK could preferentially be used in seawater hydraulic valves.

Keywords: corrosion-resistant alloys, CF-PEEK, friction and wear, seawater hydraulic valves, tribocorrosion

\section{$\underline{\text { FULL TEXT }}$}

(C) 2019 The Authors. Published by ESG (www.electrochemsci.org). This article is an open access article distributed under the terms and conditions of the Creative Commons Attribution license (http://creativecommons.org/licenses/by/4.0/). 